\title{
Stimulation of Macrophage Cells Against Cutaneous Leishmaniasis Using Silver Nanoparticles
}

\author{
Rawa F. H. Al-Saeedi
}

Entsar J. Saheb

\author{
Received 3/8/2018, Accepted 16/1/2019, Published 2/6/2019
}

This work is licensed under a Creative Commons Attribution 4.0 International License.

\begin{abstract}
:
Cutaneous leishmaniasis is a disease caused by Leishmania tropica parasite. Current treatments for this parasite are undesirable because of their toxicity, resistance, and high cost. Macrophages are key players against pathogens. Nitric oxide (NO), a molecule produce by immune cells, controls intracellular killing of pathogens during infection. Silver nanoparticles (Ag NPs) demonstrated broad-spectrum activity against various types of infectious diseases. It has the ability to stimulate oxygen species production. This study aims to analyze the macrophages activation through NO production and estimate the cytotoxicity based on the lactate dehydrogenase (LDH) release upon exposure to L. tropica and Ag NPs. Serially concentrations of Ag NPs were used under two conditions during and following macrophages exposure to L. tropica. MTT assay was used to determine the cytotoxicity of Ag NPs on L. tropica amastigotes during infection of macrophages in vitro. The results showed that by increasing the Ag NPs concentrations, the viability percentage of $L$. tropica amastigotes decreased and reached to $21.7 \pm 0.64 \%$ during infection compared with the control. The 50\% inhibitory concentration of Ag NPs on amastigotes was $2.048 \mu \mathrm{g} / \mathrm{ml}$ during infection. Moreover, post-phagocytosis study involved the assessment of NO and LDH release by macrophages upon exposure to L. tropica. It have shown that untreated macrophages released low levels of NO while in the presence of Ag NPs, macrophages were activated to produce higher levels of NO under all experimental conditions. On the other hand, macrophages were capable of controlling cytotoxicity and decreasing LDH levels during phagocytosis of $L$. tropica amastiogotes. Taking together, these findings suggest that Ag NPs can enhance macrophages NO production which provides a method for the identification of Ag NPs ligands with microbicidal and anti-cytotoxic properties against $L$. tropica pathogens.
\end{abstract}

Key words: Lactate dehydrogenase, Leishmania tropica, Macrophages, Nitric oxide, Silver nanoparticles.

\section{Introduction:}

Leishmaniasis is an infection caused by the parasitic protozoan Leishmania and it spreads by sand fly insect vector (1).The lifecycle of Leishmania spp. involves a series of differentiation processes; the procyclic promastigote procedures, infective metacyclic promastigotes in the invertebrate sand fly host, which then differentiate into amastigotes in the vertebrate host (2). The most spread type of leishmaniasis is cutaneous leishmaniasis (CL), and its infections frequently give rise to serious skin lesions and scars (3). CL is a global healthcare trouble with medical influence(4).CL still represents harmful consequences in Iraq (5).

Leishmania has recognized strategies for efficient uptake into macrophages and it is capable to regulate phagosome progress for parasite development and to escape destruction.

Department of Biology, College of Science, University of Baghdad, Baghdad, Iraq.

*Corresponding author:ejsaheb@ualr.edu
Subsequently, macrophage resistances is enhanced either by oxidative damage through nitric oxide (NO) and reactive oxygen species (ROS), antigen presentation, immune activation and apoptosis(6). Nevertheless, Leishmania decreases the NO production(7).

Lactate dehydrogenase (LDH) is a cytoplasmic enzyme. It has a role in the anaerobic glycolytic pathway through transferring $\mathrm{H}^{+}$. The oxidation of Lactate to pyruvate is catalyzed by $\mathrm{LDH}$ in the existence of nicotinamide adenine dinucleotide as hydrogen acceptor (8). In parasitic diseases, raised serum LDH levels have been described in patients with Sarcocystis (9), toxoplasmosis (10) and leishmaniasis (11).

Recent antileishmanial drug showed resistance by the parasites and the patients had problems with drug poisonousness (12). While pentavalent antimonial drugs are the most frequently prescribed treatments for leishmaniasis, they yield severe side effects, including 
hepatotoxicity and cardiotoxicity. Extra compounds, such as amphotericin B, miltefosine and pentamidine are the second choice drugs but they furthermore produce side effects that can threaten the patient's life. Nanotechnology has performed as an attractive alternative due to its enhanced bioavailability and lower toxicity, and extraphysical appearance which is important to reduce the burden of the diseases $(13,14)$. Silver nanoparticles (Ag NPs)have attained a special focus (15), as an example, the production of ROS by silver nanoparticles is an antibacterial effect (16).Therefore, this study aimed to study the stimulus effect of Ag NPs on macrophages ability to inhibit $L$. tropica infection via evaluating the level of $\mathrm{NO}$ production and $\mathrm{LDH}$ release in vitro.

\section{Material and Methods \\ Parasite Culture}

Leishmania tropica was obtained from patients attended to Al Karama Hospital, Baghdad, Iraq. The parasite was maintained at Biology Department, College of Science, University of Baghdad. The promastigotes were cultivated in 199 medium containing $50 \mu \mathrm{g} / \mathrm{ml}$ penicillin and $10 \%$ HI-FBS and incubate at $26{ }^{\circ} \mathrm{C}$ (17).

\section{Culture of Macrophage Cells}

To evaluate the antileishmanial activity of Ag NPs against the intracellular amastigotes, macrophage model, was used. The macrophage cells were isolated from the peritoneum of BALB/c mice by injection the Thioglycollate. The isolated macrophages were counted and the appropriate size completed using DMEM which supplemented with $10 \%$ fetal bovine serum. Macrophage cells were then seeded into flat- bottom 96 well microtiter plates for $24 \mathrm{hrs}$. at $37^{\circ} \mathrm{C}$ in a humidified $5 \% \mathrm{CO}_{2}, 95 \%$ air incubator. Flouting cells were removed by washing with the medium (18).

\section{Raising Infection of Metacyclic Stage Parasites in vitro}

Leishmania culture were centrifuged, washed two times with PBS (pH7.2) and resuspended in complete RPMI medium. FBS (5\%) was added to the parasite solution and incubated for $30 \mathrm{~min}$ at $37^{\circ} \mathrm{C}$ in order to gain the infective metacyclic-stage parasites. After 6 days, the metacyclic stage parasites were isolated from the cultures (19).

\section{Preparation of Ag NPs Concentrations}

Ag NPs were imported from NANO pars SPADANA Technology. The concentration of Ag NPs was $4000 \mathrm{mg} / \mathrm{L}$. The stock solution of Ag NPs was serially diluted in serum free DMEM media yielding concentrations $(0.25,0.5,1,2,4$, and
$8 \mu \mathrm{g} / \mathrm{ml})$. For establishing a homogeneous suspension, the solution was sonicatedat $100 \mathrm{~W}$ and $40 \mathrm{kHz}$ for $40 \mathrm{~min}$ and small magnetic bars was used for stirring during dilution to avoid aggregation of the particles (20).

\section{Determination Viability Percentage of $L$. tropica and Macrophages after Treatment with Ag NPs}

The antileishmanial effectiveness of $\mathrm{Ag}$ NPs was tested during macrophages exposure to $L$. tropica promastigotes, $100 \mu \mathrm{l}$ of promastigotes $\left(2 \times 10^{4}\right.$ cells/well $)$ were treated with $50 \mu 1$ serially diluted Ag NPs $(0.25,0.5,1,2,4$, and $8 \mu \mathrm{g} / \mathrm{ml})$ and incubated for $4 \mathrm{hrs}$. at room temperature. Macrophage cells and the parasites were counted using the hemacytometer. Macrophages culture were infected with Ag NPs-treated promastigotes at a ratio of 1:10 (macrophage/parasites) and incubated at $37^{\circ} \mathrm{C}$ for $48 \mathrm{hrs}$. Macrophages exposed to $L$. tropica promastigotes only was used as control. Viability percentage of the parasites and macrophages during infection were measured using the calorimetric MTT assay (21). A solution of MTT (Thiozolyl blue tetrazolium bromide) (BioWorld, USA) was added and incubated for $4 \mathrm{hrs}$. at $37^{\circ} \mathrm{C}$, the MTT solution was removed. The residual crystals in the wells were solubilized by the addition of $130 \mu \mathrm{l}$ of DMSO medium then incubated at $37^{\circ} \mathrm{C}$ for $15 \mathrm{~min}$ with shaking. The absorbency was measured on a microplate reader at $584 \mathrm{~nm}$.

\section{Macrophages Activation and CytotoxicityAssay}

Macrophages activation and cytotoxicity were measured by NO production and LDH release. The antileishmanial effectiveness of Ag NPs was tested under two conditions, during and following macrophages exposure to $L$. tropica promastigotes. For the (during) treatment, $100 \mu \mathrm{l}$ of promastigotes $\left(2 \times 10^{4}\right.$ cells/well $)$ were treated with $50 \mu 1$ serially diluted Ag NPs $(0.5,1,2,4$, and $8 \mu \mathrm{g} / \mathrm{ml})$ and incubated for $4 \mathrm{hrs}$. at room temperature. Macrophages culture was infected with Ag NPstreated promastigotes at a ratio of 1:10 (macrophage/parasites) and incubated at $37^{\circ} \mathrm{C}$ for 24 and 48 hrs. For the (following) treatment, culture was infected with $100 \mu$ l of promastigotes $\left(2 \times 10^{4}\right.$ cells/well) at a ratio of 1:10 (macrophage/parasites) and incubated at $37^{\circ} \mathrm{C}$ for $4 \mathrm{hrs}$. After their incubation, $50 \mu 1$ serially diluted Ag NPs $(0.5,1,2$, 4 , and $8 \mu \mathrm{g} / \mathrm{ml}$ ) were introduced to each culture and incubated for 24 and $48 \mathrm{hrs}$. Cell culture supernatants $(50 \mu \mathrm{l})$ were assayed for NO using Griess assay (Promega, USA) and compared with $\mathrm{NaNO}_{2}$ as a standard (22). Briefly, $50 \mu$ of cell culture supernatant was mixed with $50 \mu$ l of Griess reagent $\quad(0.1 \% \quad(\mathrm{w} / \mathrm{v}) \quad \mathrm{N}-(1 \quad$ naphthyl $)$ ethylenediaminedihydrochloride and $1 \%(\mathrm{w} / \mathrm{v})$ 
sulfanilamide in $5 \%(\mathrm{v} / \mathrm{v})$ phosphoric acid). The samples were left at room temperature for $15 \mathrm{~min}$ and the absorbance was measured at $490 \mathrm{~nm}$ using plate reader. Cell cytotoxicity was analyzed using a CytoTox96® kit (Promega, Inc., Madison, WI, USA). This kit allows measuring $\mathrm{LDH}$ in the culture supernatant (23). LDH is released when cells are lysed upon toxic effects of studied agents. In the kit, tetrazolium salt is converting to a red formazan product. The amount of color in the supernatant is related to the $\mathrm{LDH}$ release. $\mathrm{LDH}$ activity was measured at $490 \mathrm{~nm}$.

\section{The Statistical Study}

To find $\mathrm{IC}_{50}$ using excel application, $\mathrm{X}$-axis represent logarithm of concentration and $\mathrm{Y}$ - axis represent MTT density relative $\left(\mathrm{Y}_{0}\right)$, by interpolation method between two concentrations $\left(\mathrm{X}_{1}\right.$ more than $\mathrm{Y}_{0}, \mathrm{X}_{2}$ less than $\left.\mathrm{Y}_{0}\right)$ get $\mathrm{IC}_{50}$. The Statistical Analysis System- SAS (2012) program was used to study the difference factors in study parameters. Least significant difference-LSD test was utilized for the significant compare between means in this study.

\section{Results:}

The Impact of Ag NPs on Infected Macrophages

The viability of infected macrophages treated with $\mathrm{Ag}$ NPs increased with significant $(\mathrm{P}<0.05)$ differences. The lowest used concentration of Ag NPs $(0.25 \mu \mathrm{g} / \mathrm{ml})$ recorded $(92.05 \pm 3.79)$ of viable cells, while the highest concentration ( 8 $\mu \mathrm{g} / \mathrm{ml})$ recorded $(103.02 \pm 5.07)$ of viable cellscompare with the control group (macrophages infected with L. tropica and not treated with $\mathrm{Ag}$ NPs) which was $(67.461 \pm 2.83)$ (Table 1).

Table 1. Macrophages viability percentage after treatment and infection with $L$. tropica.MØ: Macrophages.

\begin{tabular}{cc}
\hline Ag NPs $(\boldsymbol{\mu g} / \mathbf{m l})$ & MØ viability \% \\
\hline 0.25 & $92.05 \pm 3.79$ \\
0.5 & $94.17 \pm 3.62$ \\
1 & $96.63 \pm 3.55$ \\
2 & $98.98 \pm 4.92$ \\
4 & $99.85 \pm 4.31$ \\
8 & $103.02 \pm 5.07$ \\
Control & $67.461 \pm 2.83$ \\
LSD value & $8.563 *$ \\
* $(\mathrm{P}<0.05)$ & \\
\hline
\end{tabular}

The Impact of Ag NPs Against L. tropica Amastigotes During Infection of Macrophages

The viability percentage of $L$. tropica amastigotes treated with $\mathrm{Ag}$ NPs during infection of macrophages decreased with significant $(\mathrm{P}<0.01)$ differences. After 48 hrs., the low concentration of
Ag NPs had the highest percentages of viable cells $(57.83 \pm 2.37)$, while the highest concentration recorded lower percentage of viability $(21.7 \pm 0.64)$ of $L$. tropica amastigotes compare with the control group (macrophages infected with $L$. tropica and not treated with Ag NPs)(Table 2). The $\mathrm{IC}_{50}$ value of Ag NPs on L. tropica amastigotes during infection of macrophages was $2.048 \mu \mathrm{g} / \mathrm{ml}$.

Table 2. Leishmania tropica viability percentages after 48 hrs. of treatment with An NPs.

\begin{tabular}{cc}
\hline Ag NPs $(\boldsymbol{\mu g} / \mathbf{m l})$ & L. tropicaviability \% \\
\hline 0.25 & $57.83 \pm 2.37$ \\
0.5 & $32.7 \pm 1.72$ \\
1 & $29.03 \pm 1.44$ \\
2 & $29.06 \pm 1.36$ \\
4 & 24.791 .03 \\
8 & $21.7 \pm 0.64$ \\
Control & $89.371 \pm 3.75$ \\
LSD value & $7.577 * *$ \\
& $* *(\mathrm{P}<0.01)$ \\
\hline
\end{tabular}

\section{Nitric Oxide (NO) Production}

The differences of NO production from macrophage cells treated with Ag NPs (during) infection with $L$. tropica for 24 and 48 hrs. were tested. The first control included only macrophages and the second control was included macrophages infected with $L$.tropica and not exposed to Ag NPs. During infection, the results showed no-significant differences of NO production after 24 and $48 \mathrm{hrs}$. of treatment with the low concentrations of Ag NPs, while the high concentrations $(8 \mu \mathrm{g} / \mathrm{ml})$ of $\mathrm{Ag}$ NPs displayed significant differences of NO production after 24 and $48 \mathrm{hrs}$. of treatment, the readings were $(0.170 \pm 0.01)$ and $(0.250 \pm 0.03)$ respectively (Table 3).

Table 3. Nitric Oxide production after 24 and 48 hrs. of treatment (during) infection [ $(L$. tropica+AgNPs) 4h+ MØ]. MØ: Macrophages.

\begin{tabular}{|c|c|c|c|}
\hline $\begin{array}{l}\text { Ag NPs } \\
(\mu \mathrm{g} / \mathrm{ml})\end{array}$ & 24 hrs. & 48 hrs. & $\begin{array}{c}\text { LSD } \\
\text { value }\end{array}$ \\
\hline 0.5 & $0.106 \pm 0.01$ & $0.159 \pm 0.02$ & $0.059 \mathrm{NS}$ \\
\hline 1 & $0.110 \pm 0.01$ & $0.177 \pm 0.01$ & $0.076 \mathrm{NS}$ \\
\hline 2 & $0.129 \pm 0.02$ & $0.181 \pm 0.02$ & $0.072 \mathrm{NS}$ \\
\hline 4 & $0.129 \pm 0.01$ & $0.210 \pm 0.02$ & $0.077 *$ \\
\hline 8 & $0.170 \pm 0.01$ & $0.250 \pm 0.03$ & $0.069 *$ \\
\hline МØ & $0.147 \pm 0.01$ & $0.233 \pm 0.02$ & $0.083 *$ \\
\hline $\begin{array}{c}\mathrm{MØ}+L . \\
\text { tropica }\end{array}$ & $0.124 \pm 0.02$ & $0.203 \pm 0.02$ & $0.071 *$ \\
\hline LSD value & $\begin{array}{c}0.077 \text { NS } \\
(\mathrm{P}<0.05), \mathrm{NS}:\end{array}$ & $\begin{array}{c}0.083 * \\
\text { Non-significant }\end{array}$ & --- \\
\hline
\end{tabular}

In addition, the results revealed differences of NO production from macrophages treated by $\mathrm{Ag}$ NPs (following) infection with L. tropica for 24 and $48 \mathrm{hrs}$. After treatment with the concentrations of 0.5 and $1 \mu \mathrm{g} / \mathrm{ml}$ of Ag NPs, the results showed no- 
significant differences of NO production, while the concentrations of 2,4 and $8 \mu \mathrm{g} / \mathrm{ml}$ of Ag NPs showed significant differences of NO production after 24 and 48 hrs. (Table 4).

Table 4. Nitric Oxide productions after 24 and 48 hrs. of treatment (following) infection [ $(L$. tropica+ MØ) 4h+ AgNPs]. MØ: Macrophages.

\begin{tabular}{|c|c|c|c|}
\hline $\begin{array}{l}\text { Ag NPs } \\
(\mu \mathrm{g} / \mathrm{ml})\end{array}$ & 24 hrs. & 48 hrs. & $\begin{array}{c}\text { LSD } \\
\text { value }\end{array}$ \\
\hline 0.5 & $0.136 \pm 0.02$ & $0.203 \pm 0.01$ & $0.072 \mathrm{NS}$ \\
\hline 1 & $0.137 \pm 0.03$ & $0.203 \pm 0.03$ & $0.069 \mathrm{NS}$ \\
\hline 2 & $0.140 \pm 0.02$ & $0.220 \pm 0.01$ & $0.071 *$ \\
\hline 4 & $0.152 \pm 0.02$ & $0.239 \pm 0.04$ & $0.068 *$ \\
\hline 8 & 0.03 & $0.304 \pm 0.03$ & $0.082 *$ \\
\hline МØ & $0.147 \pm 0.01$ & $0.233 \pm 0.02$ & $0.062 *$ \\
\hline $\begin{array}{c}\text { MØ+L. } \\
\text { tropica }\end{array}$ & $0.124 \pm 0.01$ & $0.203 \pm 0.03$ & $0.069 *$ \\
\hline LSD value & $\begin{array}{c}0.082 \mathrm{NS} \\
<0.05), \mathrm{NS}:\end{array}$ & $\begin{array}{l}0.105 \mathrm{NS} \\
\text { 1-significant. }\end{array}$ & --- \\
\hline
\end{tabular}

\section{Lactate Dehydrogenase (LDH) Release}

The differences of LDH release from macrophages treated with $\mathrm{Ag} \mathrm{NPs}$ during infectionwith L. tropica for 24 and $48 \mathrm{hr}$ were tested.After treatment with the Ag NPs during infection, the results showed significant $(\mathrm{P}<0.05)$ differences. The lowest concentration of Ag NPs recorded $(0.265 \pm 0.02)$ and $(0.514 \pm 0.03)$ after 24 and $48 \mathrm{hrs}$.However, the highest concentration of Ag NPs recorded $(0.042 \pm 0.00)$ and $(0.343 \pm 0.02)$ after 24 and $48 \mathrm{hr}$ (Table 5).

Table 5. LDH release after 24 and 48 hrs. of treatment during infection [( L. tropica+ Ag NPs) 4h+ MØ]. MØ: Macrophages.

\begin{tabular}{cccc}
\hline $\begin{array}{c}\text { AgNPs } \\
(\boldsymbol{\mu g} / \mathbf{m l})\end{array}$ & $\mathbf{2 4}$ hrs. & $\mathbf{4 8 ~ h r s .}$ & $\begin{array}{c}\text { LSD } \\
\text { value }\end{array}$ \\
\hline $\mathbf{0 . 5}$ & $0.265 \pm 0.02$ & $0.514 \pm 0.03$ & $0.114^{*}$ \\
$\mathbf{1}$ & $0.137 \pm 0.01$ & $0.490 \pm 0.03$ & $0.194^{*}$ \\
$\mathbf{2}$ & $0.063 \pm 0.01$ & $0.406 \pm 0.02$ & $0.225^{*}$ \\
$\mathbf{4}$ & $0.062 \pm 0.01$ & $0.389 \pm 0.02$ & $0.192 *$ \\
$\mathbf{8}$ & $0.042 \pm 0.00$ & $0.343 \pm 0.02$ & $0.216^{*}$ \\
$\mathbf{M \emptyset}$ & $0.129 \pm 0.01$ & $0.372 \pm 0.02$ & $0.109 *$ \\
$\begin{array}{c}\text { MØ } \boldsymbol{L} . \\
\text { tropica }\end{array}$ & $0.292 \pm 0.02$ & $0.547 \pm 0.04$ & $0.126 *$ \\
LSD value & $0.114 *$ & $0.109 *$ \\
\multicolumn{4}{c}{$*(\mathrm{P}<0.05)$, NS: Non-significant } \\
\hline \multicolumn{4}{c}{--} \\
\hline
\end{tabular}

Also, the differences of LDH release from macrophages treated by $\mathrm{Ag}$ NPs following infectionfor 24 and 48 hrs. were significant $(\mathrm{P}<0.05)$. Only the concentration $(1 \mu \mathrm{g} / \mathrm{ml})$ of $\mathrm{Ag}$ NPs showed no-significant differences between 24 and $48 \mathrm{hrs}$. The lowest concentration of Ag NPs recorded $(0.27 \pm 0.02)$ and $(0.41 \pm 0.02)$ of $\mathrm{LDH}$ release after 24 and 48 hrs. of treatment. However, the highest concentration of Ag NPs recorded (0.05 $\pm 0.00)$ and $(0.23 \pm 0.01)$ after 24 and 48 hrs. of treatment (Table 6).

Table 6. LDH release after 24 and 48 hrs. following infection $[(L$. tropica $+M \emptyset) 4 h+A g$ NPs]. MØ: Macrophages.

\begin{tabular}{cccc}
\hline $\begin{array}{c}\text { Ag NPs } \\
(\boldsymbol{\mu g} / \mathbf{m l})\end{array}$ & $\mathbf{2 4}$ hrs. & $\mathbf{4 8}$ hrs. & $\begin{array}{c}\text { LSD } \\
\text { value }\end{array}$ \\
\hline $\mathbf{0 . 5}$ & $0.27 \pm 0.02$ & $0.41 \pm 0.02$ & $0.136 *$ \\
$\mathbf{1}$ & $0.19 \pm 0.02$ & $0.32 \pm 0.02$ & $0.144 \mathrm{NS}$ \\
$\mathbf{2}$ & $0.11 \pm 0.01$ & $0.29 \pm 0.02$ & $0.136 *$ \\
$\mathbf{4}$ & $0.08 \pm 0.01$ & $0.27 \pm 0.02$ & $0.132 *$ \\
$\mathbf{8}$ & $0.05 \pm 0.00$ & $0.23 \pm 0.01$ & $0.141 *$ \\
$\mathbf{M \emptyset}$ & $0.13 \pm 0.01$ & $0.37 \pm 0.02$ & $0.133 *$ \\
MØ+ L. & $0.29 \pm 0.02$ & $0.55 \pm 0.04$ & $0.145^{*}$ \\
tropica & & & \\
LSD value & $0.163 *$ & $0.142 *$ \\
\multicolumn{4}{c}{$*(\mathrm{P}<0.05), \mathrm{NS}:$ Non-significant } \\
\hline
\end{tabular}

\section{Discussion}

Recent antileishmanial chemotherapy applications have clear side effect (24).Ag NPs have been used as an attractive alternative treatment due to its enhanced bioavailability and lower toxicity (15). This study aimed to test investigatethe stimulation effect of Ag NPs on macrophages to inhibit L. tropica infection in vitro. When the macrophages treated with Ag NPs during infection, the MTT results have shown the antileishmanial effects of Ag NPsdue to the decreasing of the $L$. tropica amastigotes viability. On the other hand, the viability of macrophages increased when treated by $\mathrm{Ag}$ NPs during infection compare with control. The Ag NPs have been revealed to be cytotoxic at a concentration more than $6 \mu \mathrm{g} / \mathrm{ml}$ (25). Although in this study, the concentration $8 \mu \mathrm{g} / \mathrm{ml}$ of Ag NPs was non-toxic. It was found that low concentrations such as 1,5 , and $10 \mu \mathrm{g} / \mathrm{ml}$ of $\mathrm{Ag}$ NPs had no toxic effects on macrophages in the dark or under UV light (16). Ag NPshave presented certain capability in generating high amounts of reactive oxygen species (ROS) in macrophages, the host cells for Leishmania parasites. ROS can cause oxidative stress and DNA damage and ultimately apoptosis of the parasite(26).

The results of (27) showed the effectiveness of Ag NPs through decreased viability of L. tropica axenic amastigotes to $10.58 \%$ in the concentration $2.1 \mu \mathrm{g} / \mathrm{ml}$. These findings suggest that Ag NPs can be used to support macrophages to eliminate parasite. Macrophages can produce sufficient amounts of ROS to kill microbial agents (28). However, Leishmania prevent this production through the inhibition of the enzymatic pathway that responsible for producing ROS, and Leishmania can live inside macrophages without exposed to any damage (29). Therefore, it may be 
suggested that to prevent Leishmania parasites with an ROS-based treatment, these oxygen products must be produced in a physical way such as using $\mathrm{Ag}$ NPs, as an alternative of the enzymatic way that can be obstructed by the parasites.

This study reveals that Ag NPs stimulates macrophages to increase the production of NO (during) and (following) infection with Leishmania. Stimulation of macrophages and the following NO production reflect the main antileishmanial element for macrophages. It has an important role in infection control, chiefly during the first stages and before the parasite protection mechanisms are started (30).Moreover, the results displayed the effectiveness of Ag NPs due to the decrease LDH release in macrophages infected with $L$. tropica. This indicates the ability of Ag NPs to inhibit $L$. tropica inside the macrophage and increase macrophages viability. Taher et al.(2016)(31) showed that there was an increase in LDH enzyme activity in visceral Leishmaniasis patients in comparison with healthy controls. Determining LDH enzyme is advantageous for cytotoxicity assays, especially if cells are exposed to the test compound and studied agents for a long time (32). Taking together, this study demonstrate that Ag NPs stimulate NO production and decrease LDH level by macrophages upon exposure of L. tropica. The more effective concentration ofAg NPs was $(8 \mu \mathrm{g} / \mathrm{ml})$ to enhance NO production under (during) and (following) to L. tropica exposure.

In brief, cutaneous leishmaniasis still represents a healthcare trouble with medical and social impact. Recent drugs that are used to treat leishmaniasis infection are accompanying with several side effects (24). Ag NPs demonstrated broad-spectrum activity against diverse types of causative agents of infectious diseases which creates the possibility to apply Ag NPs not only for treatment purposes but also for control the infections (33).

\section{Conclusion:}

The results of this study proved that $\mathrm{Ag}$ NPs is a candidate targets against $L$. tropica infection through its effect to stimulate NO production and decrease the cytotoxicity that caused by $L$. tropica amastiogotes on macrophage cells.

\section{Conflicts of Interest: None.}

\section{References:}

1. Nozzi M, Del Torto M, Chiarelli F, Breda L. Leishmaniasis and autoimmune diseases in pediatric age.Cell Immunol.2014; 292(1-2):9-13.

2. De Pablos L, Ferreira T, Walrad P. Walrad. Developmental differentiation in Leishmania lifecycle progression: post-transcriptional control conducts the orchestra. Curr. Opin. Microbiol.2016; 34:82-89.

3. Dowlati Y. Cutaneous leishmaniasis: clinical aspect. Clin. dermatol.1996; 14: 425-431.

4. Alvar J, Velez ID, Bern C, Herrero M, Desjeux P, Cano $\mathrm{J}$ et al. Leishmaniasis worldwide and global estimates of its incidence. PLoS One. 2012; 7 (5):e35671.

5. Saheb EJ. The prevalence of parasitic protozoan diseases in Iraq, 2016. Karbala International Journal of Modern Science.2018; 4: 21e25.

6. Podinovskaia M, Descoteaux A. Leishmania and the macrophage: a multifaceted interaction. Future Microbiol.2015; 10 9: 111-129.

7. Dhingra N, Satapathy S. Altercating leishmaniasis: Cultivating improved vaccines. Am J Infect Dis microbiol.2014; 2 (1): 11-16.

8. Fody E. Liver function. Clinical chemistry: principles, procedures, correlations (Bishop ML, Duben-Engelkirk JL, Fody EP, eds.), Lippincott Williams \& Wilkins, Philadelphia, PA. 2000:361387.

9. Prasse K, Fayer R. Hematology of experimental acute Sarcocystis bovicanis infection in calves. II. Serum biochemistry and hemostasis studies. Vet. Pathol.1981; 18: 358-367.

10. Sacks JJ, Delgado DG, Lobel HO, Parker RL.Toxoplasmosis infection associated with eating undercooked venison. Am. J. Epidemiol.1983; 1189: 832-838.

11. Akrawi B. Purification of LDH-1 and LD-5 isoenzymes from kala-azaric sera and studies of their chemical and physical properties. M. Sc. Thesis, College of Science, University of Baghdad. 1985.

12. Sundar S, Singh A, Singh OP. Strategies to overcome antileishmanial drugs unresponsiveness. J. Trop. Med. 2014 (2014) 646932.

13. Gutiérrez V, Seabra AB., Reguera RM., Khandare J, Calderón M. New approaches from nanomedicine for treating leishmaniasis. Chem. Soc. Rev.2016; 45: $152-168$.

14. De Almeida L, Fujimura AT, Cistia MLD, FonsecaSantos B, Imamura KB, Michels PA, Chorilli M, Graminha MA. Nanotechnological Strategies for Treatment of Leishmaniasis-A Review. J. Biomed. Nanotechnol. 2017; 13(2): 117-33.

15. Ahmed S, Ahmad M, Swami BL, Ikram S. A review on plants extract mediated synthesis of silver nanoparticles for antimicrobial applications: a green expertise. J. Adv. Res.2016; 7 9: 17-28.

16. Allahverdiyev AM, Abamor ES, Bagirova M, Ustundag CB, Kaya C, Kaya F, Rafailovich M. Antileishmanial effect of silver nanoparticles and their enhanced antiparasitic activity under ultraviolet light. Int. J. Nanomedicine.2011; 6: 2705-2714.

17. Al-Bashir NT, Rassam MB, Al-Rawi BM. Axenic cultivation of amastigotes of Leishmania donovani and Leishmania major and their infectivity. Ann. Trop. Med. Parasitol. 1992; 86 (5), 487-502.

18. Jena P, Mohanty S, Mallick R, Jacob B, Sonawane A. Toxicity and antibacterial assessment of chitosancoated silver nanoparticles on human 
pathogens and macrophage cells. Int. J. Nanomedicine. 2012; 7, 1805.

19. Manandhar KD, Yadav TP, Prajapati VK, Kuma S, Rai M, Dube A,Srivastava ON, Sundar S. Antileishmanial activity of nano-amphotericin B deoxycholate. J. Antimicrob. Chemother. 2008; 62(2), 376-380.

20. Gatta A, Jawad M, Bahjat A, Al-ani N, Ali A. Antimicrobial activities of geranium extract and silver, copper nanoparticles.IJBPR. 2015; 6: 84-86.

21. Slater TF, Sawyer B, Sträuli U. Studies on succinatetetrazolium reductase systems: III. Points of coupling of four different tetrazolium salts III. Points of coupling of four different tetrazolium salts. Biochim. Biophys. Acta. 1963; 77, 383-393.

22. Campos-Neto A, Ovendale P, Bement T, Koppi TA, Fanslow WC, Rossi MA, Alderson MR. Cutting edge: CD40 ligand is not essential for the development of cell-mediated immunity and resistance to Mycobacterium tuberculosis. J. Immunol. 1998; 160 (5), 2037-2041.

23. Brander C, Wyss-Coray T, Mauri D, Bettens F, Pichler WJ. Carrier-mediated uptake and presentation of a major histocompatibility complex class Irestricted peptide. Eur. J. Immunol. 1993; 23(12), 3217-3223.

24. Sundar S, Singh A, Singh OP. Strategies to overcome antileishmanial drugs unresponsiveness. J. Trop. Med. 2014; 2014.

25. Lara HH, Garza-Treviño EN, Ixtepan-Turrent L, Singh, DK. Silver nanoparticles are broad-spectrum bactericidal and virucidal compounds. J. Nanobiotechnology. 2011; 9: 30.

26. Dolat E, Rajabi O, Salarabadi SS, Yadegari-Dehkordi S, Sazgarnia A. Silver nanoparticles and electroporation: Their combinational effect on Leishmania major. Bioelectromagnetics.2015; 36: 586-596.

27. Gharby MA, AL-Qadhi BN, Jaafar SM. Evaluation of Silver Nanoparticles (Ag NPs) Activity Against the Viability of Leishmania tropica Promastigotes and Amastigotes In Vitro. Iraqi Journal of Science.2017; 58: 13-21.

28. Lodge R, Descoteaux A. Phagocytosis of Leishmania donovani amastigotes is Rac1 dependent and occurs in the absence of NADPH oxidase activation. Eur. J. Immunol.2006; 36: 2735-2744.

29. Mehta A, Shaha C.Mechanism of metalloid-induced death in Leishmania spp. role of iron, reactive oxygen species, $\mathrm{Ca} 2+$, and glutathione. Free Radic. Biol.Med. 2006; 40: 1857-1868.

30. Sadeghi S, Seyed N, Rafati S, Taheri T. Optimization of the Timing of Induction for the Assessment of Nitric Oxide Production in Leishmania major Infected Macrophage Cells. Iran. J. Parasitol. 2016; 11: 325 .

31. Taher JH, Hummadi YMKAM, AL-Bashir NMT, AL-Araji AS. Lactate dehydrogenase (LD), alkaline phosphatase (ALP) isoenzymatic patterns in Iraqi children with visceral leishmaniasis before and after treatment with stibogluconate. J. Parasit. Dis. 2016; $1(8)$.

32. Riss T, Moravec R. Introducing the CytoTox-ONE ${ }^{\mathrm{TM}}$ homogeneous membrane integrity assay". Promega Corporation. (2002).

33. Rai $\mathrm{M}$, Kon $\mathrm{K}$, Ingle $\mathrm{A}$, Duran $\mathrm{N}$, Galdiero $\mathrm{S}$, Galdiero M. Broad-spectrum bioactivities of silver nanoparticles: the emerging trends and future prospects.Appl. Microbiol. Biotechnol. 2014; 98(5): 1951-1961. 
تحفيز الخلايا البلعمية ضد الاصابة باللثمانيا الجلدية باستخدام جزيئات الفضة المتناهية الصغر

انتصار جبار صاحب

\author{
رؤى فارس حسين السعيدي
}

قسم علوم الحياة، كلية العلوم، جامعة بغداد، بغداد، العراق.

الخلاصة.

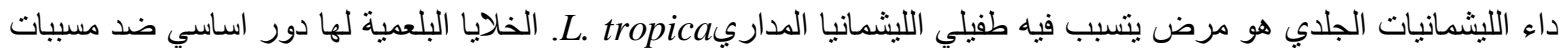

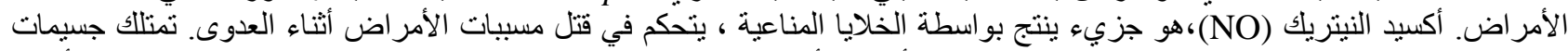

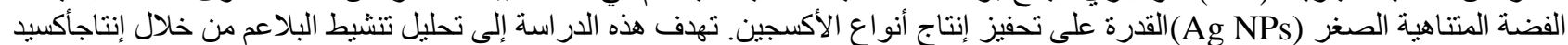

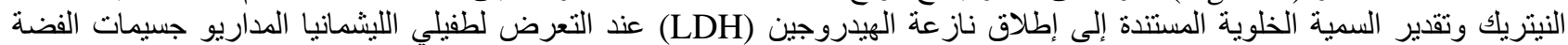

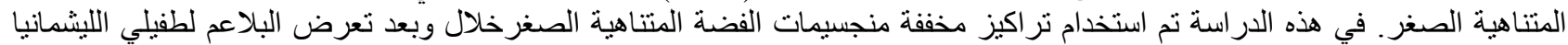

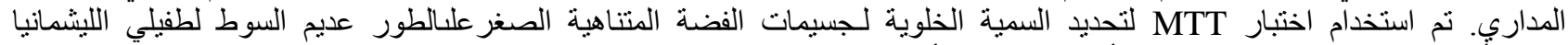

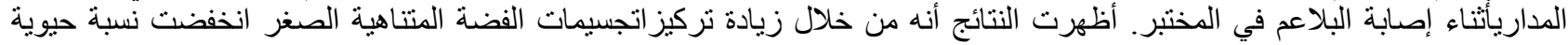

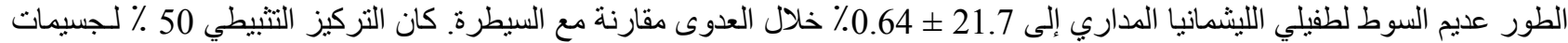

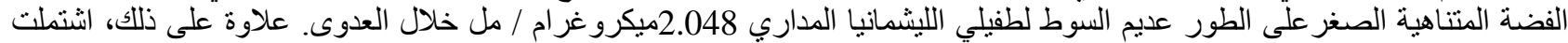

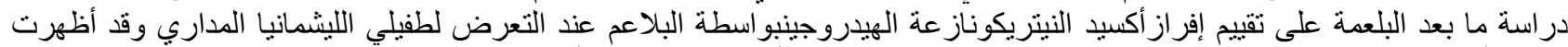

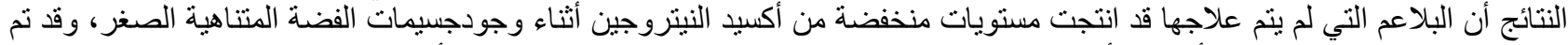

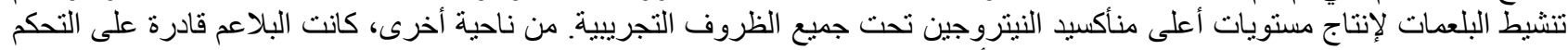

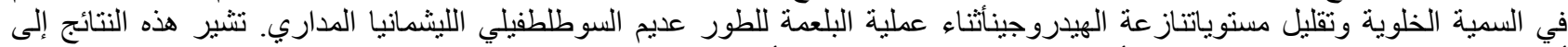

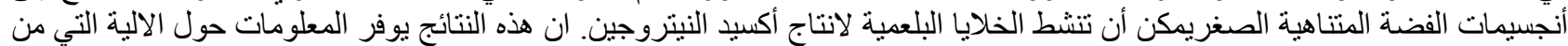
خلالها تسنطيع جسيمات الفضة المتتاهية الصغر السيطرة على الاصابة بالميكروبات وتحفيز الخلايا المضادة للسمية ضد مسببات الليشمانيا المداري.

الكلمات المفتاحية: ناز عة الهيدروجين، الليشمانيا المدارية، البلاعم، أكسيد النيتريك، جسيمات الفضة المتناهية الصغر. 